\title{
Rancang Bangun Keamanan Port Secure Shell (SSH) Menggunakan Metode Port Knocking
}

\author{
Desmira $^{\mathrm{a}, 1}$, Romi Wiryadinata ${ }^{\mathrm{b}, 1}$ \\ ${ }^{a}$ Fakultas Keguruan dan Ilmu Pendidikan UNTIRTA (FKIP UNTIRTA), Banten 42117, Indonesia \\ ${ }^{b}$ Fakultas Teknik UNTIRTA, Teknik Elektro, Universitas Sultan Ageng Tirtayasa, Banten 42435, Indonesia \\ E-mail:' wiryadinata@untirta.ac.id,2desmira@untirta.ac.id
}

\begin{tabular}{|c|c|}
\hline INFORMASI ARTIKEL & ABSTRAK \\
\hline $\begin{array}{l}\text { Kata Kunci: } \\
\text { Port ssh, Remote } \\
\text { Administrator server } \\
\text { Port Knocking } \\
\text { Pengamanan dan Pengawasan } \\
\text { Jaringan Internet. }\end{array}$ & $\begin{array}{l}\text { PT. Banten Tour Mandiri merupakan penyedia layanan Tour dan Travel, } \\
\text { kebutuhan dalam penggunaan internet pada perusahaan sangat dibutuhkan agar } \\
\text { pelayanan dalam bidang jasa dapat terlaksana dengan nyaman dan efektif. } \\
\text { Penelitian ini bertujuan 1.Merancang sistem remote menggunakan port } \\
\text { knocking untuk memmantau dan mengawasi akses jaringan internet pada PT. } \\
\text { Banten Tour Mandiri. 2. Mengawasi jaringan internet pada lingkungan PT. } \\
\text { Banten Tour Mandiri. 3. Memudahkan perusahaan dalam mengelola, mengawasi } \\
\text { saat menggunakan jaringan internet yang ada di lingkungan perusahaan. Untuk } \\
\text { mengembagkan kesetabilan jaringan internet yang ada, namun ada beberapa hal } \\
\text { yang belum diperhatikan dan diimplementasikan, yaitu keamanan dan } \\
\text { pengawasan terhadap jaringan internet, maka dibutuhkannya suatu sistem } \\
\text { keamanan jaringan yang mempermudah pengamanan dan pengawasan, dengan } \\
\text { malakukan Rancang Bangun Kemanan Port Secure Shell (SSH) Menggunakan } \\
\text { Metode Port Knocking Di PT. Banten Tour Mandiri. Hasil penelitian ini terlihat } \\
\text { administrator berhasil melakukan akses remote terhadap server jaringan internet } \\
\text { menggunakan port ssh. Pemantauan dan pengelolaan keamanan jaringan } \\
\text { internet dapat dilakukan menggunakan PC yang berbeda yang berada pada } \\
\text { lingkukan PT. Banten Tour Mandiri }\end{array}$ \\
\hline
\end{tabular}

Keywords:

SSH port,

Remote.

server administrator

Port Knocking,

Internet Network

Security and Monitoring

\section{ABSTRACT}

PT. Banten Tour Mandiri is a tour and travel service provider, the need for internet use in companies is very much needed so that services in the service sector can be carried out comfortably and effectively. This study aims 1. To design a remote system using port knocking to monitor and supervise internet network access at PT. Banten Tour Mandiri. 2. Overseeing the internet network at PT. Banten Tour Mandiri. 3. Make it easier for companies to manage, supervise when using the existing internet network in the corporate environment. To develop the stability of the existing internet network, but there are several things that have not been considered and implemented, namely security and supervision of the internet network, it is necessary to have a network security system that simplifies security and supervision, by performing the Secure Shell (SSH) Port Security Design Port Knocking Method At PT. Banten Tour Mandiri. The results of this study show that the administrator has successfully performed remote access to the internet network server using the SSH port. Monitoring and management of internet network security can be done using a different PC located in the PT. Banten Tour Mandiri

\section{Pendahuluan}

Keamanan jaringan merupakan pengembangan yang sangat penting dalam dunia teknologi karena keamanan adalah salah satu pokok yang dibutuhkan dalam kalangan termasuk perusahaan. Keamanan merupakan sumber utama bagi kelancaran suatu usaha yang bergerak dalam bidang jasa tour dan travel dikarenakan perusahaan yang bergerak dalam bidang jasa sangat membutuhkan kesetabilan akses jaringan internet dan pengembangan dunia digital. Jaringan internet sudah meluas dan digunakan dalam kalangan selain perorangan dan perusahaan jaringan internet dapat digunakan oleh anak-anak yang mencari berbagai sumber informasi seputar mater pembelajaran atau sekedar informasi biasa, perusahaan pun demikian membutuhkan sumber informasi yang cepat dan akurat dengan memanfaatkan dunia digital khusus nya jaringan internet. PT. Banten Tour Mandiri merupakan perusahaan yang bergerak dalam pelayanan jasa tour dan travel, dalam melakukan kegiatan perusahaan memiliki beberapa perangkat jaringan internet dan keamanan tersendiri, 
namun masih banyaknya perusahaan-perusahaan mikro menghiraukan tentang keamanan jaringan. Dalam keamanan jaringan terdapat beberapa perkembangan-perkembangan dalam melakukan keamanan jaringan yang sangat meluas, perkembangan itu sendiri dibutuhkan untuk menutupi kekurangan-kekurangan dalam keamanan jaringan tersebut.

Berhubungan dengan hal itu, administrator jaringan dituntut bekerja lebih untuk dapat mengamankan jaringan komputer yang dikelolanya. Salah satu bentuk keamanan jaringan yang sering digunakan oleh seorang administrator jaringan dalam pengelolaan server yaitu melalui remote login seperti Secure Shell (SSH). Akses remote server ini berfungsi untuk melakukan pemantauan dan pengawasan terhadap jaringan internet server terpusat, dan dapat memudahkan administrator jaringan internet untuk pengelolaan dengan akses remote server menggunakan post SSH melakukan penelitian tentang firewall filter berbasis mikrotik untuk mengawasi kegiatan yang sedang berlangsung di Laboratorium Komputer, untuk meningkatkan keamanan dalam jaringan menggunakan sistem geteway sekaligus sebagai firewall yang menerapkan packet filtering dimana metode packet filtering akan mengatur semua paket baik yang menuju,melewati atau akan ditujuh packet tersebut [1]melakukan penelitian tentang "analisis keamanan jaringan nirkabel menggunakan Wireless Intrusion Detection System (WIDS). Kinerja dari WIDS mampu mendeteksi serangan DOS (Denial of Service)".

Penelitian ini menerapkan OS linux dari serangan keamanan jaringan[2]melakukan "penelitian tentang aplikasi monitoring keamanan jaringan dengan menggunakan IDS dan Router Mikrotik"[3]. Intrusion Detection System merupakan sistem pencegahan penyusupan. Penelitian ini menggunakan web untuk mempermudah administrator dalam memonitoring jaringan internet melakukan penelitian tentang analisis “ delay yang terjadi pada penerapan Demilitarized Zone (DMZ) terhadap server. Dalam menjaga keamanan jaringan komputer dan server maka dikembangkan berbagai metode perlindungan di antaranya firewall DMZ (Demiliterized Zone) [4]"merancang sebuah keamanan jaringan dengan metode packet filtering firewall yang nantinya berguna untuk mengamankan jaringan internal(private/LAN) di PT. Sukses Berkat Mandiri" [5] Perbandingan dengan penelitian yang dibuat port SSH yang digunakan dalam penelitian ini menggunakan metode port knocking. Mempermudah dalam pengelolaan dan pengamanan jaringan pada saat berjalan nya akses internet, karena menggunakan opensource yaitu berbasis linux.

Dalam sistem keamanan ini, hanya membutuhkan beberapa konfigurasi dalam port SSH dan port knocking. Fungsi dari sistek yang dibuat penulis merupakan akses kusus keamanan jaringan dalam pengelolaan dan pengawasan dari setiap akses jaringan internet yang ada dalam lingkungan perusahaan, karna kemudahan dalam pengelolaan dan akses rahasia yang dapat digunakan hanya administrator tertentu.

PORT SSH (Secure Shell) SSH banyak digunakan dalam kemanan jaringan komputer bahkan digunakan dalam keamanan jaringan sebuah perusahaan-perusahaan besar di indonesia.

SSH adalah protokol jaringan yang memungkinkan pertukaran data melalui saluran aman antara dua perangkat jaringan, terutama banyak digunakan pada sistem berbasis linux (UNIX Like) dan Unix untuk mengakses shell SSH dirancang sebagai pengganti telnet dan shell remote tidak lainnya yang mengirim informasi, terutama kata sandi, dalam bentuk plain text yang membuatnya mudah untuk disadap.

Keamanan Jaringan merupakan salah satu aspek terpenting dalam sebuah jaringan. Akan tetapi seringkali masalah keamanan jaringan dipandang sebelah mata. Selama ini para administrator jaringan hanya berusaha untuk membuat pertahanan sebaik-baiknya seperti menggunakan firewall dan Intrusion Detection System (IDS) agar jaringan lebih aman. Namun hanya melindungi dari karakteristik serangan yang dikenali. Selain itu administrator tidak bisa banyak mempelajari dari implementasi firewall mengenai serangan yang terjadi untuk mengetahui tujuan dari serangn

\section{Metode}

Penelitian ini Menerapkan metode port knocking pada jaringan internet. Dengan menganalisa beberapa hal yang perlu dipertimbangkan dalam penulisan ini .

Pertama : Permasalah yang ada di tempat penelitian dengan melakukan observasi [6] [7] ke PT. Banten Tour Mandiri

1. Belum ada nya sistem keamanan yang berjalan.

2. Belum ada sebuah sarana pendukung untuk perkembangan keamanan jaringan internet pada perusahaan.

Kedua : Dengan melakukan wawancara dengan staff dan teknisi yang ada di PT. Banten Tour Mandiri

Ketiga : Pengambilan data penelitian dengan melakukan beberapa yaitu dengan menganalisa jaringan yang ada di PT. Banten Tour Mandiri. 


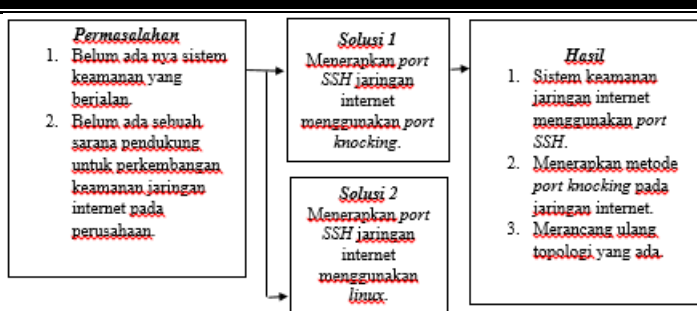

Gambar 1 kerangka fikir penelitian di PT. Banten Tour Mandiri

\section{Hasil Dan Pembahasan}

Manajemen jaringan pada PT. Banten Tour Mandiri merupakan sekumpulan komputer yang masih berhubungan, sedangkan untuk pusat jaringan masih menggunakan perangkat wireless yang di sebar kebeberapa PC menggunakan kabel LAN.

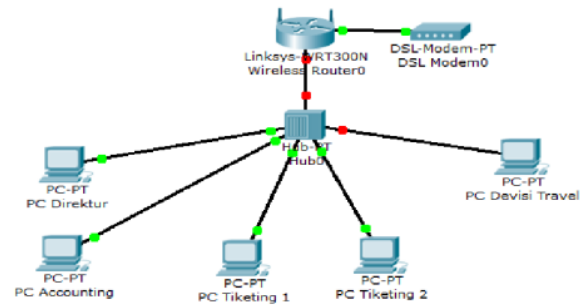

Gambar 2 Topologi Jaringan Komputer PT. Banten Tour Mandiri

Topologi yang digunakan pada PT. Banten Tour Mandiri, yaitu topologi star mengunakan kabel antar sebagai penghubung wirelles ke modem indihome, kemudian untuk akses internet menggunakan hotspot dan LAN yang berada dilingkungan PT. Banten Tour Mandiri menghubungkan access point yang berada dibeberapa titik dan di beberapa tempat lainnya.

Pada Gambar 2 merupakan gambar topologi jaringan pada PT. Banten Tour Mandiri terdapat beberapa PC yang digunakan untuk client dan PC Direktur. Dalam jaringan internet ini PT. Banten Tour Mandiri menggunakan ip address kelas $\mathrm{C}$.

Arsitektur jaringan server komputer menggunakan tp-link router sebagai penghubung antara modem atau ISP Telkom IndiHome kemudian, diteruskan menggukan access point sebagai penyebar hotspot untuk client di lingkungan PT. Banten Tour Mandiri

Skema jaringan LAN (Local Area Network) menggunakan komputer yang sudah terinstal Windows menggunakan topologi star. Skema ini akan digunakan pada PT. Banten Tour Mandiri untuk mengimplementasikan remote server menggunakan port SSH.

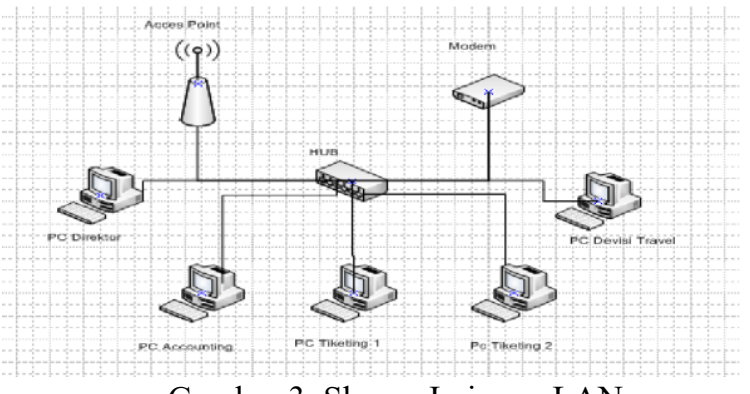

Gambar 3. Skema Jaringan LAN

Di dalam sebuah jaringan dibutuhkan beberapa perangkat keras (hardware) ataupun perangkat lunak (software), sebagai berikut:

Perangkat keras yang digunakan pada PT. Banten Tour Mandiri meliputi beberapa komputer server, client, router, modem, access point, switch atau hub dan perangkat pendukung lainnya. Perangkat lunak yang digunakan windows sebagai sistem operasi untuk server, sistem operasi windows 7 sebagai sistem operasi yang digunakan untuk client dan hardware yang digunakan

Permasalahaan yang terdapat pada PT. Banten Tour Mandiri sebagai berikut :

1.Belum adanya suatu rancangan sistem yang mengamankan jaringan internet pada PT. Banten Tour Mandiri .

Desmira $^{\mathrm{a}, 1}$, Romi Wiryadinata ${ }^{\mathrm{b}, 1}$ [Rancang Bangun Keamanan Port Secure Shell (SSH) Menggunakan Metode

Port Knocking] 
2.Belum adanya port SSH untuk memantau keamanan jaringan internet pada perusahaan.

Topologi jaringan komputer yang akan dirancang menggunakan topologi star, selain mudah dalam konfigurasi topologi ini dapat menstabilkan keamanan jaringan ketika ada kendala pada akses jaringan.

Modem atau ISP yang digunakan terhubung langsung PC Server yang berada pada ruang server PT. Banten Tour Mandiri kemudian terhubung ke hub dan switch untuk disebarkan kepada client dengan LAN.

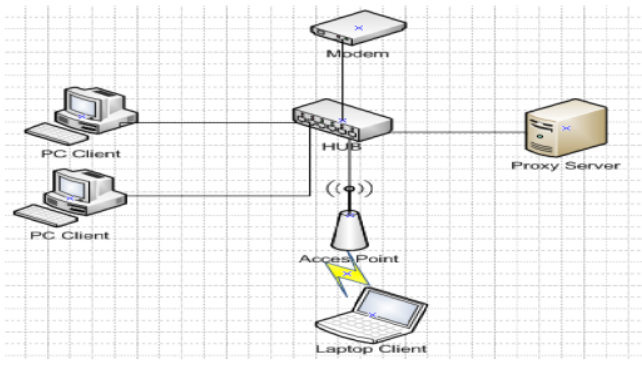

Gambar 3. Skema jaringan usulan di PT. Banten Tour Mandiri

Pada keamanan jaringan menggunkan metode port knocking dimana pada suatu port tertentu di ubah dan di konfigurasikan dengan metode port knocking. Keamanan jaringan ini menggunkan port ssh sebagai targer keamanan pada proxy server. Bertujuan agar akses kedalam jaringan server hanya untuk hak akses administrator.

Rancangan Aplikasi Install SSH Konfigurasi yang penulis lakukan pertaman kali dengan install SSH pada terminal Ubuntu 14.04

sudo su

apt-get install openssh-server

apt-get install openssh-client

apt-get install ssh

langkah selanjutnya agar port ssh dapat berjalan dengan lancar, maka konfigurasi selanjutnya dengan mengedit srcript pada file sshd_config, dengan menggunakan perintah berikut.

Nano /etc/ssh/sshd_config

File yang akan diedit oleh penulis yaitu port 22 menjadi port 222. Sebelum menjalankan ssh penulis merubah password access login ssh menjadi (azat) dengan perintah password root. Setelah selesai edit file yang diperlukan selanjutnya restart ssh dengan perintah, service ssh restart.

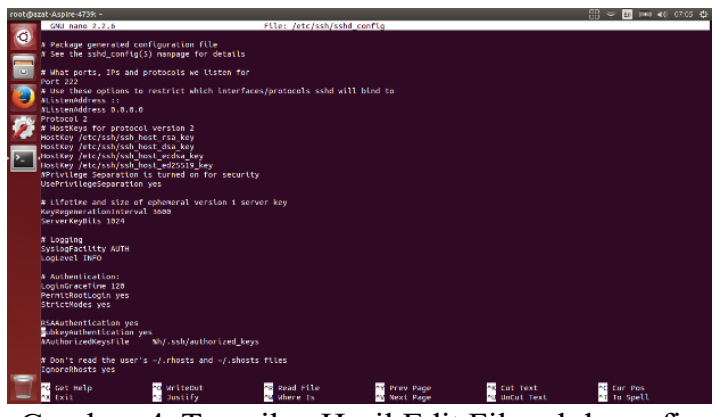

Gambar. 4. Tampilan Hasil Edit File sshd_config

Install Port Knocking Pada saat intalansi dan kofigurasi port knocking penulis menambahkan paket iptables untuk meminimalisir dampak serangan dari peretas. Berikut langkah-langkah instalasi.

Apt-get install knockd

Apt-get install iptables

Iptables -flush

Iptables - t nat-flush

Iptables -t mangle-flush

Iptables - policy OUTPUT ACCEPT

Selanjutnya melakukan pengalamatan port ssh dengan perintah iptables $-A$ INPUT - $m$ CONNTRACK -ctstate ESTABLISHED, RELATED -j ACCEPT dan iptables - A INPUT - p tcp-destination-port $222-j$ DROP. Setelah selesai maka install paket pendukung lainnya dengan perintah. apt-get install iptables-persistent. Pengertian

Desmira $^{\mathrm{a}, 1}$, Romi Wiryadinata ${ }^{\mathrm{b}, 1}$ [Rancang Bangun Keamanan Port Secure Shell (SSH) Menggunakan Metode

Port Knocking] 
iptables adalah sebuah intruksi pada system opration linux Ubuntu dalam mengatur suatu jaringan internet.

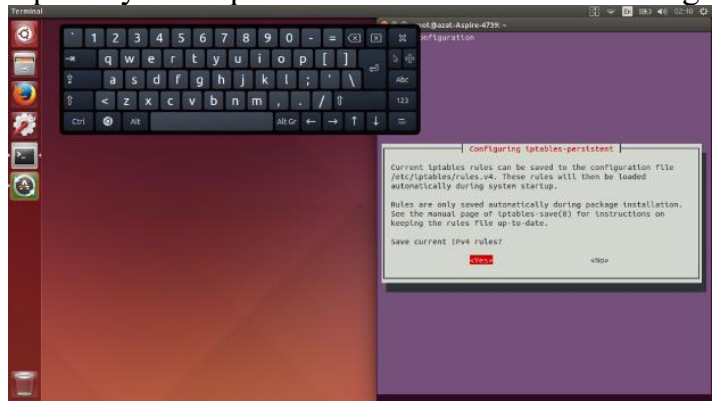

Gambar 5. Tampilan instalasi iptables

Pengujian awal penulis menggunakan windows 7 untuk memantau akses jaringan yang ada pada PT. Banten Tour Mandiri menggunakan netstat dan belum adanya remote access pada PC Server. Netstats merupakan intruksi pada system opration windows untuk melakukan pengecekan dan pemantauan aktifitas port-port yang terdapat pada server.

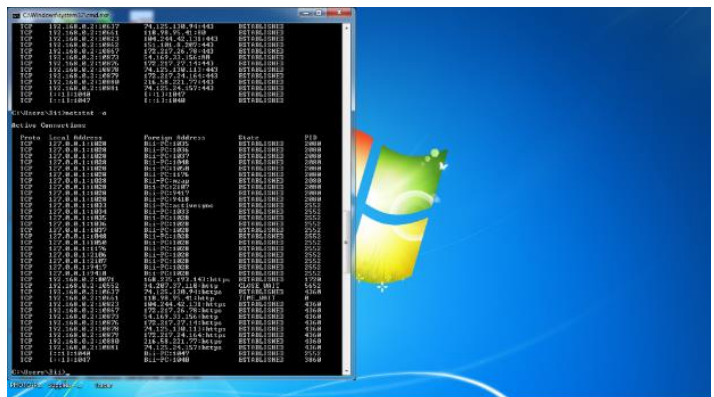

Gambar 6. Tampilan Access monitoring jaringan

Pada pengujian akhir penulis menggunakan linux Ubuntu sebagai, akses jaringan server menggunakan SSH, dan linux sebagai server jaringan pada PT. Banten tour Mandiri.

Pada pemantauan sebelum nya menggunakan inturksi netstat ada beberapa port pada jaringan server diantaranya port 433 , sebelumnya penulis melakukan konigurasi pada jaringan server dengan mengubah port SSH menjadi 222 dengan demikian sistem operasi windows tidak dapat melihat aktifitas port ssh pada jaringan server.

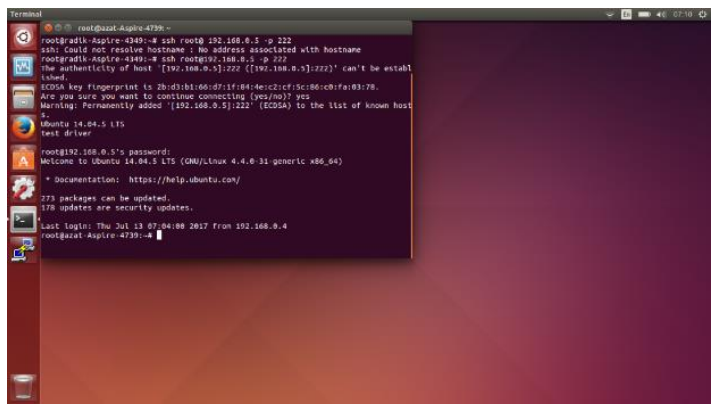

Gambar 7. Tampilan Access remote ssh

Pada gambar 8 terdapat dua user pengguna yang dimana root@radik-Aspire-4349:-\# sebagai ssh client dan root@azat-Aspire-4739:-\# sebagai server jaringan. Sistem operasi yang digunakan berbasis linux Ubuntu. Pengujian akhir penulis melakukan uji coba dengan menggunakan sistem operasi linux Ubuntu dengan melakukan perintah ssh root@192.168.0.5 -p 222 pada terminal linux Ubuntu client. IP address 192.168.0.5 merupakan IP address dari jaringan linux server sedangkan 222 adalah port yang dibuat oleh penulis. 


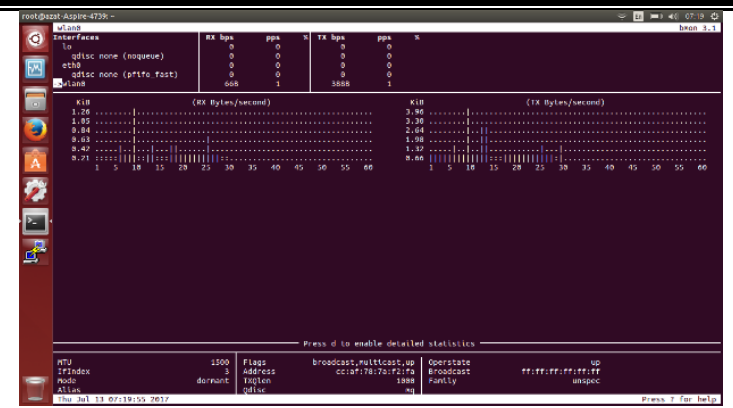

Gambar 8. Tampilan Access monitoring jaringan SSH

Pada tampilan gambar 8, penulis mengakses jaringan server menggunakan ssh yang digunakan untuk remote dan monitoring jaringan pada server dengan menggunakan terminal Ubuntu client.

Setelah melaukan remote menggunakan port ssh, administrator dapat memantau aktifitas jaringan pada linux server. Selain menggunakan linux Ubuntu uji coba pada jaringan linux server dapat dilakukan menggunakan sistem operasi windows dengan bantuan aplikasi putty.exe.

Tujuan dalam pemantauan jaringan linux server menggunakan port ssh merupakan kebutuhan dalam menujang kegiatan administrator server dalam pengawasan dan pemantauan aktifitas jaringan internet pada server. Port ssh dapat dilakukan di tempat yang berbeda dengan akses jaringan yang sama LAN.

Analisis

Dari hasil akhir terdapat beberapa perubahan pada akses $\neg$ server dengan menggunkan port ssh, administrator mempunyai hak akses dalam pengawasan dan pengelolaan kemanan pada server dengan menggunakan metode port knocking.

\section{IV.KESIMPULAN}

Berdasarkan penelitian yang telah dilakuan, ada beberapa hal yang penulis simpulkan, yaitu :

a) Untuk membangun konfigurasi Port SSH dapat dilakukan dengan metode Port Knocking.

b) Pemanfaatan Port SSH yang mudah konfortible dan praktis dalam memantau jaringan internet pada server.

c) Perlunya sistem keamanan pada jaringan internet pada perusahaan-perusahaan dalam akses kedalam server

\section{REFERENSI}

[1] I. G. Komang, O. Mardiyana, I. G. Komang, and O. Mardiyana, "Keamanan Jaringan Dengan Firewall Filter Berbasis Mikrotik Pada Laboratorium Komputer STIKOM Bali,” no. 86, pp. 9-10, 2015.

[2] R. Mentang, A. A. E. Sinsuw, X. B. N. Najoan, and J. T. Elektro-ft, "Perancangan Dan Analisis Keamanan Jaringan Nirkabel Menggunakan Wireless Intrusion Detection System,” vol. 5, no. 7, pp. 35-44, 2015.

[3] A. Hamzah, M. Sholeh, and T. Informatika, "Jurnal JARKOM Vol . 3 No . 1 Juni 2015 ISSN : 23386304 Jurnal JARKOM Vol . 3 No . 1 Juni 2015 ISSN : 2338-6304,” vol. 3, no. 1, pp. 6-15, 2015.

[4] S. Ikhwan, "Vol : 3 No . 2 September 2014 ANALISA DELAY YANG TERJADI PADA PENERAPAN DEMILITARIZED ZONE ( DMZ ) TERHADAP SERVER UNIVERSITAS ANDALAS Jurnal Nasional Teknik Elektro Jurnal Nasional Teknik Elektro,” no. 2, pp. 118-124, 2014.

[5] “No Title," vol. IV, no. 2, pp. 182-192, 2016.

[6] D. R. Papini, F. Studies, and E. Building, "An Observational Study of Affective and Assertive Family Interactions During Adolescence," vol. 17, no. 6, pp. 477-492, 1988.

[7] “A Method for Observing and Evaluating Writing Lab Tutorials on JSTOR.”. 